\title{
Emergency Management of Anaphylaxis in Chinese Primary Care Units: Systematic Analysis of 77 Cases
}

\section{Chunyan Jiang ( $\sim$ jchy12368@sina.com )}

Capital Medical University Affiliated Beijing Friendship Hospital Hongwei Li

Capital Medical University Affiliated Beijing Friendship Hospital

\section{Lina Wang}

Capital Medical University Affiliated Beijing Friendship Hospital

Chunyan Liu

Capital Medical University Affiliated Beijing Friendship Hospital

Xiaofei Hao

Capital Medical University Affiliated Beijing Friendship Hospital

\section{Research}

Keywords: Anaphylaxis, Management, Primary Care, Chinese

Posted Date: May 13th, 2020

DOI: https://doi.org/10.21203/rs.3.rs-27009/v1

License: (c) (1) This work is licensed under a Creative Commons Attribution 4.0 International License. Read Full License 


\section{Abstract}

Background Anaphylaxis is a potentially fatal medical emergency and prompt, appropriate administration of epinephrine is critical. However, the actual clinical practices of emergency management of anaphylaxis in Chinese primary care remain unclear.

Objective To evaluate the actual emergency management of anaphylaxis in Chinese primary care units compared to current guidelines.

Methods Systematic analysis of published case reports of anaphylaxis initially treated in Chinese primary care units from January 2014 through December 2018.

Results A total of 77 cases were included in this analysis. The patients came from 22 provinces of China. Mean age was 42 years, and $49(64.5 \%)$ were male. All the patients developed severe anaphylactic reactions, with mortality rate of $5.2 \%$. Only $21(27.3 \%)$ patients received epinephrine as first-line intervention. The first dose of epinephrine ranged from $0.0625 \mathrm{mg}$ to $0.5 \mathrm{mg}$ in children and $0.1 \mathrm{mg}$ to $1.0 \mathrm{mg}$ in adults. The percentage of adult patients who received initial epinephrine dose of $1.0 \mathrm{mg}$ (73.7\%) was significantly higher than that of $0.5 \mathrm{mg}(19.3 \% ; p<0.001)$. The percentage of patients who received subcutaneous (SC), intramuscular (IM), or intravenous (IV) bolus injection was $44.3 \%, 36.1 \%$, and $19.7 \%$, respectively. Among patients who received epinephrine, $80.3 \%$ received an overdose. All the 5 patients who developed serious adverse effects associated with epinephrine had received an overdose, and 4 of these had received route of IV bolus injection.

Conclusion and Clinical Relevance The actual emergency management of anaphylaxis in Chinese primary care is not consistent with current guidelines. Under-use, overdose and inappropriate route of epinephrine administration are the major problems. Targeted training is therefore strongly suggested for Chinese general practitioners.

\section{Introduction}

Anaphylaxis is a life-threatening medical emergency and prompt appropriate emergency management is critical. International guidelines published by the World Allergy Organization (WAO), the European Academy of Allergy and Clinical Immunology (EAACl), the American Academy of Allergy, Asthma and Immunology (AAAAI), and the American College of Allergy, Asthma and Immunology (ACAAI) concur with the recommendations of intramuscular (IM) injection of epinephrine in the mid-outer thigh as first-line treatment for anaphylaxis, whereas inhaled $\mathrm{B} 2$-adrenergic agonists, $\mathrm{H} 1$ - and $\mathrm{H} 2$-antihistamines, and glucocorticoids are regarded as second or third-line medications ${ }^{[1-3]}$.

General practitioners play an important role in the management of anaphylaxis. However, prevalent clinical practices with respect to emergency treatment of anaphylaxis in Chinese primary care units are not well identified. Limited studies found under-use and/or inappropriate use of epinephrine during treatment of anaphylaxis in China ${ }^{[4-6]}$, but all these studies were investigated in large hospitals in Beijing 
before the year of 2014; in addition, these reports did not provide specific information about the critical initial treatment of anaphylaxis.

Accordingly, we evaluated the actual emergency treatment of anaphylaxis initially treated in Chinese primary care units by analyzing published cases during period of 2014 to 2018 . The objective was to identify the gaps between current clinical practices of initial treatment of anaphylaxis in Chinese primary care units and current guidelines, so as to provide further suggestions for improvement of anaphylaxis management in primary care in China.

\section{Materials And Methods}

\section{Search strategy}

According to the Preferred Reporting Items for Systematic Review and Meta-analysis (PRISMA) guidelines, we searched online literature through several international and Chinese databases including PubMed, ScienceDirect, Web of Science, Wanfang database (http:// med.wanfangdata.com.cn), China National Knowledge Internet database (http://www.cnki.net), and VIP database (http://www. cqvip.com). The following key words were used for the literature search: "anaphylaxis", "anaphylactic reaction", "anaphylactic reactions", "reaction, anaphylactic", "reactions, anaphylactic", "anaphylactic shock", "shock, anaphylactic", "kounis syndrome", "kounis" and "china". In addition, the reference lists of the retrieved articles were manually screened to identify additional eligible studies.

\section{Selection criteria}

Case reports pertaining to anaphylaxis that qualified the following criteria were included: (a) with definite diagnosis of anaphylaxis based on the anaphylaxis guidelines ${ }^{[1-3,7]}$; (b) initially treated in Chinese primary care units; (c) availability of complete records of the trigger, symptoms and signs, initial treatment, specific dosage and route of epinephrine if used, and outcome; (d) published between January 1, 2014 to December 31, 2018; (e) published in Chinese or English. The exclusion criteria were as the following: (a) duplicate publication; (b) with insufficient data for diagnosis and/or specific emergency medical therapy for anaphylaxis; (c) cardiac arrest occurred before the first administration of epinephrine.

\section{Data extraction}

The retrieved articles were screened by 4 investigators. Data pertaining to the following variables were collected: (1) patient characteristics: age, sex, region, allergic history, and risk factors; (2) trigger details: type, route, and time to onset; (3) anaphylactic symptoms: skin-mucosal manifestations, cardiovascular complications, respiratory compromise, gastrointestinal symptoms, etc.; (4) first-line intervention: posture, removal of trigger, medication (epinephrine or non-epinephrine, e.g. glucocorticoids, B2-adrenergic agonists, $\mathrm{H} 1$-antihistamine, $\mathrm{H} 2$-antihistamine, vasopressors other than epinephrine, or other medications), supplemental oxygen, intravenous fluids, or other treatments; (5) dosage, administration route, and adverse effects of epinephrine; (6) outcomes. 


\section{Adjudication}

The physician adjudicators (H.L. and C.J.) independently reviewed each case to validate the diagnosis of anaphylaxis and evaluate the dose and route of epinephrine administration and associated incidence of adverse effects. Disagreements, if any, were resolved by consensus.

The diagnosis of anaphylaxis was validated using the international guidelines ${ }^{[1-3,7]}$. Overdose of epinephrine for anaphylaxis was defined as a dose that exceeded the dose recommended by anaphylaxis guidelines, i.e., $0.01 \mathrm{mg} / \mathrm{kg}$ of $1: 1000$ solution with a maximal dose of $0.5 \mathrm{mg}$ in adults or $0.3 \mathrm{mg}$ in children for IM and SC routes, or $0.001 \mathrm{mg} / \mathrm{kg}$ of $1: 10000$ solution or 1:100000 solution with a maximal dose of $0.1 \mathrm{mg}$ for slow IV injection ${ }^{[1,3,7,8]}$.

Cardiovascular adverse effects were defined according to Campbell et al ${ }^{[8]}$. Hypertension was defined as systolic blood pressure $\geq 180 \mathrm{~mm} \mathrm{Hg}$ and/or diastolic blood pressure $\geq 120 \mathrm{~mm} \mathrm{Hg}$. Cardiac ischemia was determined based on both elevated troponin T level and symptoms of cardiac ischeamia. Angina pectoris was defined as chest pressure, tightness or pain without elevation of troponin T level. Stroke was defined as onset of new neurologic deficit. The criteria for evaluation of adverse effects associated with epinephrine were: (1) cases for whom both the administered dose of epinephrine and the route of administration was reported; (2) the onset of cardiovascular complications developed after epinephrine administration; and (3) without concurrent use of epinephrine-like agents (e.g., ephedrine, norepinephrine, hydroxylamine, or dopamine).

\section{Statistical analysis}

Statistical analyses were performed with SPSS version 20.0 (SPSS Chicago, IL). Normality of distribution of continuous variables was assessed using single-sample Kolmogorov-Smirnov test. Comparisons between continuous variables were performed by the independent sample $t$ test or nonparametric rank test (Mann-Whitney U-test); Comparisons between categorical variables were performed by the Chisquared test or the Fisher's exact test. Statistical significance was set as $P<.05$ and all tests were 2sided.

\section{Results}

\section{Clinical characteristics}

A total of 7,579 articles were reviewed and 77 patients were eligible for the present analysis (Fig. 1). The patients came from 22/31 (71.0\%) provinces of China (Table 1). Shandong, Jiangsu, Henan, Anhui and Hubei were the top 5 provinces that accounted for the most number of patients $(12,9,7,5$, and 5 , respectively).

Table 2 listed patient characteristics. Median age was 42 years, and 49 (64.5\%) were male. Only $24.7 \%$ patients had a history of allergy. The primary triggers of anaphylaxis were antibiotics (44.2\%), vaccines 
(9.1\%), traditional Chinese medicine (7.8\%), insect venom (6.5\%), foods (5.2\%), and antiviral agents (5.2\%). With respect to the mode of trigger, IV infusion (59.7\%) was the most common route, followed by IM injection (14.3\%), oral administration (9.1\%), sting (6.5) and SC injection (6.2\%). The median time from exposure to the onset of anaphylaxis was 14.3 minutes. All the 77 patients developed severe anaphylactic reactions (hypotension and/or respiratory distress) and 4 of them (5.2\%) died.

\section{Emergency management of anaphylaxis}

Supplemental oxygen (49.4\%) was the most commonly administered initial treatment (Table 3). $74.7 \%$ of the patients received oxygen therapy via nasal catheter; $12.7 \%$ were administered via face mask. Only $27.3 \%$ of the patients received epinephrine as first-line intervention. Glucocorticoids were most commonly administered drugs during the course of anaphylaxis. Out of 77 patients, $73(94.8 \%)$ were administered glucocorticoids, of which dexamethasone accounted for $97.3 \%$; whereas 64 (83.1\%) received epinephrine during the course of anaphylaxis.

\section{Dose and route of epinephrine administration}

The dose of epinephrine ranged from $0.0625 \mathrm{mg}$ to $0.5 \mathrm{mg}$ among children (age <18 years) and $0.1 \mathrm{mg}$ to1.0 $\mathrm{mg}$ among adults (age $\geq 65$ years) (Table 4$)^{[9-12]}$. Among 4 children with available data on dose and route of epinephrine administration, 3 received an overdose of epinephrine, and only 1 received epinephrine intramuscularly. Among 57 adult patients with available data on epinephrine dose and route, $46(80.7 \%)$ received an overdose of epinephrine, of them 42 (73.7\%) received an initial dose of $1.0 \mathrm{mg}$; only 11 adult patients $(19.3 \%$; $p<0.001)$ received a recommended initial dose of $0.5 \mathrm{mg}$. The number of adult patients who received epinephrine by the route of SC, IM, and IV bolus injection was 25 (43.9\%), 21 $(36.8 \%)$, and $11(19.3 \%)$, respectively.

\section{Adverse effects of epinephrine}

Among the 64 patients who received epinephrine, 5 developed serious adverse effects associated with epinephrine (Table 5), including 2 cases of hypertension, 1 case of ventricular arrhythmias, 1 case of myocardial ischeamia, and 1 case of pulmonary edema. All of them had received an overdose of epinephrine; and 4 of them had received epinephrine by IV bolus injection.

\section{Discussion}

To our knowledge, this is the first study that assessed the actual emergency management of anaphylaxis in Chinese primary care by analyzing treatment details in reported cases. To evaluate the appropriateness of clinical practice in Chinese primary care against the guidelines, we analyzed the use of epinephrine as first-line intervention, as first-line medication, and during the whole course of anaphylaxis.

Epinephrine is life-saving for anaphylaxis because of its alpha-1adrenergic effects on preventing and relieving anaphylactic shock as well as airway obstruction. Failure to use it promptly may lead to fatality, 
hypoxic ischemic encephalopathy, or biphasic anaphylaxis ${ }^{[13,14]}$. International guidelines concur with recommendation of epinephrine as first-line drug for treatment of patients with confirmed or suspected anaphylaxis ${ }^{[15]}$. However, as shown in our data, there are considerable under-use of epinephrine as firstline treatment in anaphylaxis in Chinese primary care. Moreover, compared to epinephrine, glucocorticoids seem to be more frequently used in Chinese anaphylactic cases. This may imply a general lack of awareness of the appropriate emergency treatment in anaphylaxis among Chinese primary care providers.

According to internationals guidelines, as the first-line medication choice in anaphylaxis, epinephrine should be injected intramuscularly in the mid-outer thigh at a dose of $0.01 \mathrm{mg} / \mathrm{kg}$ of a 1:1000 $(1 \mathrm{mg} / \mathrm{mL})$ solution, up to a maximum of $0.5 \mathrm{mg}$ in adults and $0.3 \mathrm{mg}$ in children ${ }^{[1-3]}$. However, the first dose of epinephrine showed in this analysis ranged from $0.0625 \mathrm{mg}$ to $1.0 \mathrm{mg}$, and $80.3 \%$ patients had received an overdose of epinephrine. In China, epinephrine is only available in the form of $1 \mathrm{mg}: 1 \mathrm{~mL}$ (1:1000) ampules, while other concentrations or epinephrine auto-injectors are not available. Another possible reason may be the lack of clarity about appropriate dosage and route of epinephrine administration for different indications, e.g., a first IV bolus dosage of $1 \mathrm{mg} \mathrm{(1:10000)}$ is recommended for cardiac arrest ${ }^{[16-}$ 18].

Two pharmacokinetic studies conducted in children and adults demonstrated that, compared to SC injection in the arm, IM injection of epinephrine into the mid-outer thigh is more effective and is therefore recommend by guidelines as the preferred route of epinephrine administration in anaphylaxis ${ }^{[19,20]}$. The SC or inhalational routes for epinephrine are not recommended owing to the lower efficacy. However, most of the patients in this study were treated with epinephrine via SC injection (44.3\%), and $19.7 \%$ of the patients received IV bolus injection. Data pertaining to the site of injection was available only for 2 patients, and neither of them received epinephrine in accordance with the recommended site of injection.

In patients with adequate circulation, IV injection of epinephrine may cause serious, life-threatening adverse effects. Slow IV infusion, but not IV bolus injection, is considered only when anaphylaxis is refractory to IM injection of regular doses or anaphylactic shock is imminent or has developed. Currently, there is no established dosage for IV infusion of epinephrine in anaphylaxis ${ }^{[3]}$. A prospective study demonstrated the efficacy of a 1:100000 solution of epinephrine administered intravenously by infusion pump at the initial rate of $2-10 \mathrm{mg} / \mathrm{min}$ and titrated according to the clinical response or side effects ${ }^{[21}$, 22]. It is suggested that IV epinephrine for anaphylaxis should be administered under the guidance of those experienced in the use of vasopressors (anesthetists, emergency physicians, etc.) and under close hemodynamic monitoring ${ }^{[23]}$. In the present study, 4 of the 5 patients who developed life-threatening adverse effects received epinephrine by IV bolus injection, indicating which is a potentially harmful route of epinephrine administration in anaphylaxis.

Our study indicates that the actual emergency treatment of anaphylaxis in Chinese primary care does not comply with current guidelines. Consistent with the previous study including more inpatients ${ }^{[24]}$, under- 
use, overdose, and inappropriate administration route of epinephrine were identified as the major problems. Notably, none of these problems was noticed or discussed in these publications. This may imply a general lack of awareness about the appropriate dose and route of epinephrine for anaphylaxis in many Chinese primary care providers. Our findings call for more efforts to change this situation. In 2017, Chinese expert consensus of penicillin skin test developed by the Expert Committee on Clinical Application of Antibiotics and Evaluation of Bacterial Resistance of the National Health and Family Planning Commission recommended IM or SC injection of epinephrine for treatment of anaphylactic shock $^{[25]}$. Meanwhile, the guidelines for clinical drug use in the Pharmacopoeia of the People's Republic of China (2015 Edition) also recommend SC or IM route of epinephrine administration for treatment of anaphylaxis in adults. Therefore, we strongly underline the need to update the Chinese guidelines for treatment of anaphylaxis in accordance with the international guidelines. In addition, a targeted nationwide educational program about the international anaphylaxis management guidelines should be implemented to facilitate optimal patient care. Moreover, as recommended, written emergency protocol for diagnosis and management of anaphylaxis may be posted in primary care facilities and rehearsed regularly just like cardio-pulmonary resuscitation (CPR).

\section{Limitations}

Although reported cases may not be entirely representative of the actual clinical practices, systematic analysis of published case reports was the only feasible way for us to determine emergency treatment details in these patients nationwide. To minimize the risk of bias, we have established rigorous inclusion/exclusion criteria and performed a thorough literature search to include more cases of anaphylaxis initially treated in Chinese primary care units. Moreover, we searched Chinese literature to increase the yield of cases and to improve the representativeness of our findings.

\section{Conclusion}

There are some critical gaps between actual emergency management of anaphylaxis in Chinese primary care and international anaphylaxis guidelines. Under-use, overdose and inappropriate route of epinephrine administration are the major problems identified in this analysis. Targeted training in this respect is strongly suggested for Chinese primary care providers.

\section{Declarations}

Authors' contributions: C.J. and H.L. designed study; C.J., L.W., C.L., and X.H performed study; C.J. analyzed data; and C.J. wrote the paper.

Conflict of Interest Disclosures: There are no conflicts of interest to declare. 
Availability of data and materials: Yes, they are available.

Acknowledgements: The authors thank Prof. Haijun Wang and Prof. Ling Zhang for their guidance on methodology and approval of this manuscript.

Funding: No funding was received.

Consent for publication: Consent for publication is not applicable for review of published cases.

Ethics approval: Not applicable. Our institution does not require ethical approval for reporting review of published cases.

\section{References}

1 Simons FER, Ardusso LRF, Bilo MB, et al. for the World Allergy Organization. World Allergy Organization guidelines for the assessment and management of anaphylaxis. J Allergy Clin Immunol 2011;127:58793.e1-e22.

2 A Muraro, G Roberts, M Worm, et al. Anaphylaxis: guidelines from the European Academy of Allergy and Clinical Immunology. Allergy 2014;69(8):1026-45.

3 Lieberman P, Nicklas RA, Randolph C, et al. Anaphylaxis - a practice parameter update 2015. Ann Allergy Asthma Immunol 2015;115(5):341-84.

4 Jiang N, Yin J, Wen L, Li H. Characteristics of Anaphylaxis in 907 Chinese Patients Referred to a Tertiary Allergy Center: A Retrospective Study of 1,952 Episodes. Allergy Asthma Immunol Res 2016;8(4):353-61.

5 Tang R, Xu HY, Cao J, et al. Clinical Characteristics of Inpatients with Anaphylaxis in China. Biomed Res Int 2015;2015:429534.

6 Wang T, Ma X, Xing Y, et al. Use of Epinephrine in Patients with Drug-Induced Anaphylaxis: An Analysis of the Beijing Pharmacovigilance Database. Int Arch Allergy Immunol 2017;173(1):51-60. 
7 Sampson HA, Munoz-Furlong A, Campbell RL, et al. Second symposium on the definition and management of anaphylaxis: summary report: Second National Institute of Allergy and Infectious Disease/Food Allergy and Anaphylaxis Network Symposium. J Allergy Clin Immunol 2006;117(2):391-7.

8 Campbell RL, Bellolio MF, Knutson BD, et al. Epinephrine in Anaphylaxis: Higher Risk of Cardiovascular Complications and Overdose After Administration of Intravenous Bolus Epinephrine Compared with Intramuscular Epinephrine. J Allergy Clin Immunol 2015;3(1):76-80.

9 Lin HR, Wen RY. A case of anaphylactic shock caused by varicella vaccination. Strait J Prevent Med 2014;20(3):95. (in Chinese)

10 Kong XH, Ma YF, Yan TT. A case of anaphylactic shock caused by cefoperazone sodium and Sulbactam Sodium for injection. J Pharm Res 2017;36(8):494. (in Chinese)

11 Yang ZY. A case of anaphylactic shock caused by zedoary turmeric oil injection. Med Front 2014;4(21):269. (in Chinese)

12 Li JS. Treatment of anaphylactic shock caused by aminomethylbenzoic acid injection. Med Front 2017;7(35):18-19. (in Chinese)

13 Confino-Cohen R, Goldberg A. Allergen immunotherapy-induced biphasic systemic reactions: incidence, characteristics, and outcome: a prospective study. Ann Allergy Asthma Immunol 2010;104(1):73-8.

14 Bautista E, Simons FER, Simons KJ, et al. Epinephrine fails to hasten hemodynamic recovery in fully developed anaphylactic shock. Int Arch Allergy Immunol 2002;128(2):151-64.

15 Simons FE, Ardusso LR, Bilò MB, et al. International consensus on (ICON) anaphylaxis. World Allergy Organ J 2014;7(1):9.

16 Kanwar M, Irvin CB, Frank JJ, Weber K, Rosman H. Confusion about epinephrine dosing leading to iatrogenic overdose: a life-threatening problem with a potential solution. Ann Emerg Med 2010;55(4):341-4.

17 American Heart Association.2015 American Heart Association Guidelines Update for Cardiopulmonary Resuscitation and Emergency Cardiovascular Care. Circulation 2015;132(18 Suppl 2):S315-S482.

18 Jiang C, Li H. Electrocardiographic Changes After Overdose of Epinephrine in a Patient With Anaphylaxis: Kounis Syndrome or Epinephrine? JAMA Intern Med 2019;179(7):973-974.

19 Simons FE, Roberts JR, Gu X, Simons KJ. Epinephrine absorption in children with a history of anaphylaxis. J Allergy Clin Immunol 1998;101(1 Pt 1):33-7. 
20 Simons FE, Gu X, Simons KJ. Epinephrine absorption in adults: Intramuscular versus subcutaneous injection. J Allergy Clin Immunol 2001;108(5):871-3.

21 Field JM, Hazinski MF, Sayre MR, et al. Part 1: executive summary: 2010 American Heart Association guidelines for cardiopulmonary resuscitation and emergency cardiovascular care. Circulation 2010;122(suppl 3):S640-56.

22 Brown SG, Blackman KE, Stenlake V, Heddle RJ. Insect sting anaphylaxis; prospective evaluation of treatment with intravenous adrenaline and volume

resuscitation. Emerg Med J 2004;21(2):149-54.

23 Soar J, Pumphrey R, Cant A, et al. Emergency treatment of anaphylactic reactions-guidelines for healthcare providers. Resuscitation 2008;77(2):157-69.

24 Jiang C, Li H, Wang L, Liu C, Hao X. Gaps between actual initial treatment of anaphylaxis in China and international guidelines: a review and analysis of 819 reported cases. Allergy 2019 Epub ahead of print. doi: 10.1111/all.14090.

25 Expert Committee on Clinical Application of Antibiotics and Evaluation of Bacterial Resistance of the National Health and Family Planning Commission. Expert consensus on penicillin skin test. Natl Med J China 2017;97(40):3143-6.

\section{Tables}

Table 1. Geographic distribution of the included patients with anaphylaxis 


\begin{tabular}{|l|c|c|}
\hline Province/autonomous regions / municipality, $\mathrm{n}(\%)$ & Patients with available data, $\mathrm{n}$ & Value \\
\hline Shandong & 77 & $12(15.6)$ \\
\hline Jiangsu & 77 & 9 (11.7) \\
\hline Henan & 77 & $7(9.1)$ \\
\hline Anhui & 77 & $5(6.5)$ \\
\hline Hubei & 77 & $5(6.5)$ \\
\hline Liaoning & 77 & $4(5.2)$ \\
\hline Xinjiang & 77 & $4(5.2)$ \\
\hline Fujian & 77 & $3(3.9)$ \\
\hline Guangdong & 77 & $3(3.9)$ \\
\hline Guangxi & 77 & $3(3.9)$ \\
\hline Guizhou & 77 & $3(3.9)$ \\
\hline Hebei & 77 & $3(3.9)$ \\
\hline Jilin & 77 & $3(3.9)$ \\
\hline Shanghai & 77 & $3(3.9)$ \\
\hline Beijing & 77 & $2(2.6)$ \\
\hline Heilongjiang & 77 & $2(2.6)$ \\
\hline Hunan & 77 & $1(1.3)$ \\
\hline Inner Mongolia & 77 & $1(1.3)$ \\
\hline Qinghai & 77 & $1(1.3)$ \\
\hline Shaanxi & 77 & $1(1.3)$ \\
\hline Yunnan & 77 & $1(1.3)$ \\
\hline Zhejiang & 77 & $1(1.3)$ \\
\hline
\end{tabular}

The patients were widely distributed across 22 provinces/autonomous regions /municipalities in mainland China. Shandong, Jiangsu, Henan, Anhui and Hubei were the top 5 provinces where the most number of patients with anaphylaxis (12, 9, 7, 5, and 5, respectively) were included in this study.

Table 2. Characteristics of the included patients with anaphylaxis 


\begin{tabular}{|c|c|c|}
\hline & Patients with available data, $\mathrm{n}$ & Value \\
\hline Age, median (minimum-maximum), years & 74 & $42(2-84)$ \\
\hline$<18, \mathrm{n}(\%)$ & 74 & $5(6.8)$ \\
\hline $18-44, \mathrm{n}(\%)$ & 74 & $32(43.2)$ \\
\hline $45-64, \mathrm{n}(\%)$ & 74 & $22(29.7)$ \\
\hline$\geq 65, \mathrm{n}(\%)$ & 74 & $15(20.3)$ \\
\hline Male, n (\%) & 76 & $49(64.5)$ \\
\hline Positive allergic history, $\mathrm{n}(\%)$ & 77 & $19(24.7)$ \\
\hline \multicolumn{3}{|l|}{ Risk factors, n (\%) } \\
\hline Acute infection & 77 & $41(53.2)$ \\
\hline CVD & 77 & $3(3.9)$ \\
\hline Asthma & 77 & $1(1.3)$ \\
\hline \multicolumn{3}{|l|}{ Triggers } \\
\hline \multicolumn{3}{|l|}{ Type, n (\%) } \\
\hline Antibiotics & 77 & $34(44.2)$ \\
\hline Vaccines & 77 & $7(9.1)$ \\
\hline TCM (injection) & 77 & $6(7.8)$ \\
\hline Venom & 77 & $5(6.5)$ \\
\hline Foods & 77 & $4(5.2)$ \\
\hline Antiviral agents & 77 & $4(5.2)$ \\
\hline NSAIDs & 77 & $3(4.5)$ \\
\hline Antispasmodic agents & 77 & $2(3.3)$ \\
\hline Others & 77 & $12(15.6)$ \\
\hline \multicolumn{3}{|l|}{ Route, n (\%) } \\
\hline IV infusion & 77 & $46(59.7)$ \\
\hline IM & 77 & $11(14.3)$ \\
\hline $\mathrm{PO}$ & 77 & $7(9.1)$ \\
\hline Sting & 77 & $5(6.5)$ \\
\hline SC & 77 & $4(5.2)$ \\
\hline IV injection & 77 & $2(2.6)$ \\
\hline ID & 77 & $2(2.6)$ \\
\hline Time of exposure to onset, median (minimum - maximum), min & 65 & $14.3(1-180)$ \\
\hline \multicolumn{3}{|l|}{ Severity of the anaphylaxis, $\mathrm{n}(\%)$} \\
\hline Severe & 77 & $77(100.0)$ \\
\hline Moderate & 77 & $0(0)$ \\
\hline Mild & 77 & $0(0)$ \\
\hline \multicolumn{3}{|l|}{ Outcome, n (\%) } \\
\hline Recovery & 77 & $73(94.8)$ \\
\hline Death & 77 & $4(5.2)$ \\
\hline
\end{tabular}

Data presented as frequency (\%) unless indicated otherwise. Data for the analysis of age, gender, allergic history, risk factors, triggers, time of exposure to onset, severity of the anaphylaxis, and outcomes were available for 74, 76, 77, 77, 77, 65, 77, and 77 patients, respectively. CVD, cardiovascular disease; TCM, traditional Chinese medicine; NSAIDs, nonsteroidal anti-inflammatory drugs non-steroid anti-inflammatory drugs; IV, intravenous; IM, intramuscular; PO, per oral; SC, subcutaneous; ID, intradermal.

] Table 3. Treatment of the included patients with anaphylaxis 


\begin{tabular}{|c|c|c|}
\hline & Patients with Available Data, $\mathrm{n}$ & Value \\
\hline \multicolumn{3}{|c|}{ First-line treatment, n (\%) } \\
\hline Oxygen & 77 & $38(49.4)$ \\
\hline Epinephrine & 77 & $21(27.3)$ \\
\hline Glucocorticoid & 77 & $10(13.0)$ \\
\hline Fluid & 77 & $5(6.5)$ \\
\hline H1-antihistamine & 77 & $2(2.6)$ \\
\hline Aminophylline & 77 & $1(1.3)$ \\
\hline \multicolumn{3}{|c|}{ First-line medication, $\mathrm{n}(\%)$} \\
\hline Epinephrine & 77 & $46(59.7)$ \\
\hline Glucocorticoid & 77 & $21(27.3)$ \\
\hline H1-antihistamine & 77 & $8(10.4)$ \\
\hline Vasopressor & 77 & $1(1.3)$ \\
\hline Aminophylline & 77 & $1(1.3)$ \\
\hline
\end{tabular}

Treatment during the course of anaphylaxis, $\mathrm{n}(\%)$

\begin{tabular}{|c|c|c|}
\hline Glucocorticoids & 77 & $73(94.8)$ \\
\hline Dexamethasone & 73 & $71(97.3)$ \\
\hline Methylprednisolone & 73 & $2(2.7)$ \\
\hline Epinephrine & 77 & $64(83.1)$ \\
\hline Oxygen & 77 & $58(75.3)$ \\
\hline Nasal catheter & 58 & $56(96.6)$ \\
\hline Fa ce mask & 58 & $2(3.4)$ \\
\hline \begin{tabular}{|r|} 
Fluid support \\
\end{tabular} & 77 & $52(71.2)$ \\
\hline Glucose solution & 52 & $22(42.3)$ \\
\hline Normal saline & 52 & \begin{tabular}{l|l} 
& $18(34.6)$ \\
\end{tabular} \\
\hline Balanced solution & 52 & $3(5.8)$ \\
\hline Colloid solution & 52 & $3(5.8)$ \\
\hline Glucose saline & 52 & $1(1.9)$ \\
\hline Unspecified & 52 & $5(9.6)$ \\
\hline $\mathrm{H} 1$-antihistamines & 77 & $37(48.1)$ \\
\hline Vasopressors & 77 & $11(14.3)$ \\
\hline $\mathrm{H} 2$-antihistamines & 77 & $2(2.6)$ \\
\hline \begin{tabular}{|c|} 
Inhaled beta-2 agonists \\
\end{tabular} & 77 & $0(0)$ \\
\hline
\end{tabular}

Data presented as frequency (\%) unless indicated otherwise. Oxygen (49.4\%), epinephrine (27.3\%), and glucocorticoid (13.0\%) were the top 3 most commonly administered first-line interventions. In the analysis of first-line medications, 46 patients (59.7\%) were administered epinephrine, followed by glucocorticoids (27.3\%) and Hi--antihistamine agents (10.4\%). Glucocorticoids were the most commonly administered drugs during the course of anaphylaxis $(94.8 \%)$.

Table 4. Initial Dosage and route of administration of Epinephrine 


\begin{tabular}{|c|c|c|c|c|c|c|c|}
\hline \multicolumn{8}{|c|}{ Initial Administration of Epinephrine in Patients with Available Data } \\
\hline \multirow{2}{*}{$\begin{array}{l}\text { Group } \\
\text { (n) }\end{array}$} & \multirow{2}{*}{$\begin{array}{c}\text { Dosage } \\
\text { (mg) }\end{array}$} & \multicolumn{5}{|c|}{ Route (n) } & \multirow{2}{*}{$\begin{array}{l}\text { Overdose } \\
\text { (n) }\end{array}$} \\
\hline & & $\mathrm{M}$ & $\mathrm{SC}$ & IV injection & Unspecified & Total & \\
\hline \multirow{5}{*}{$\begin{array}{c}\text { Children } \\
\text { (5) }\end{array}$} & 0.5 & 0 & 1 & 0 & 0 & 1 & 1 \\
\hline & 0.3 & 1 & 0 & 0 & 0 & 1 & 1 \\
\hline & 0.1 & 0 & 0 & 1 & 0 & 1 & 1 \\
\hline & 0.0625 & 0 & 1 & 0 & 1 & 2 & 0 \\
\hline & Total & 1 & 2 & 1 & 1 & 5 & 3 \\
\hline \multirow{8}{*}{$\begin{array}{l}\text { Adults } \\
(59)\end{array}$} & 1.0 & 13 & 22 & 7 & 0 & $42^{*}$ & 42 \\
\hline & 0.7 & 0 & 0 & 1 & 0 & 1 & 1 \\
\hline & 0.5 & 6 & 3 & 2 & 0 & 11 & 2 \\
\hline & 0.3 & 0 & 0 & 1 & 0 & 1 & 1 \\
\hline & 0.2 & 1 & 0 & 0 & 0 & 1 & 0 \\
\hline & 0.1 & 1 & 0 & 0 & 0 & 1 & 0 \\
\hline & Unspecified & 0 & 0 & 0 & 2 & 2 & NA \\
\hline & Total & 21 & 25 & 11 & 2 & 59 & 46 \\
\hline Total & & 22 & 27 & 12 & 3 & 64 & 49 \\
\hline
\end{tabular}

Data presented as frequency (n) unless indicated otherwise. In adults, the percentage of patients who received a dose of $1.0 \mathrm{mg}$ (73.7\%) was significantly higher than that of $0.5 \mathrm{mg}(19.3 \% ; \chi 2=33.886, p<0.001)$. The number of patients who received IM, SC and IV bolus injection was 22 (36.1\%), 27 (44.3\%), and 12 (19.7\%), respectively. Among the 61 patients with record of both the epinephrine dose and the route, 49 (80.3\%) patients received an overdose of epinephrine. IM, Intramuscular; SC, Subcutaneous; IV, intravenous; NA, not available. ${ }^{*} \mathrm{p}<0.01$ versus $0.5 \mathrm{mg}$.

Table 5. Serious adverse effects associated with epinephrine administration

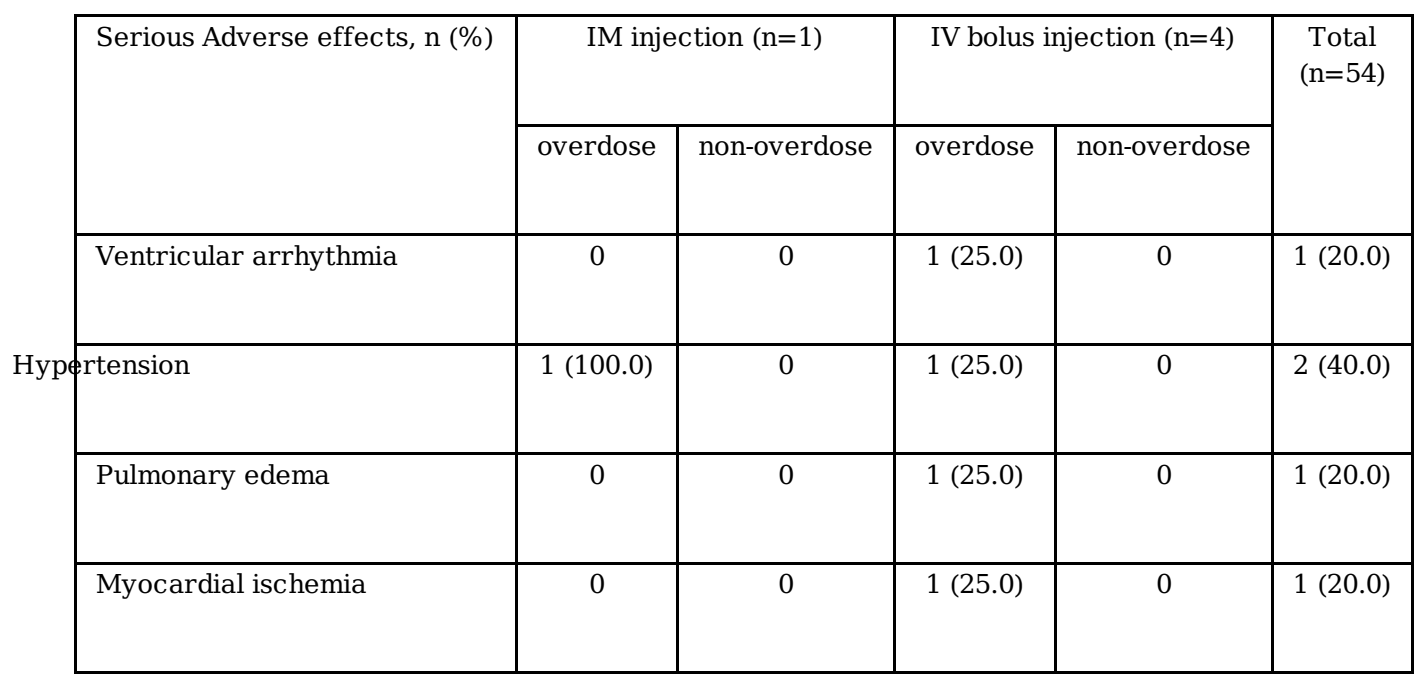

Data presented as frequency (\%) unless indicated otherwise. Out of a total of 64 patients who received epinephrine, 5 patients (7.8\%) developed serious adverse effects associated with epinephrine. All the 5 patients received an overdose, and 4 of them were administered by IV bolus injection. IM, Intramuscular; SC, Subcutaneous; IV, intravenous; NA, not available. 


\section{Figures}

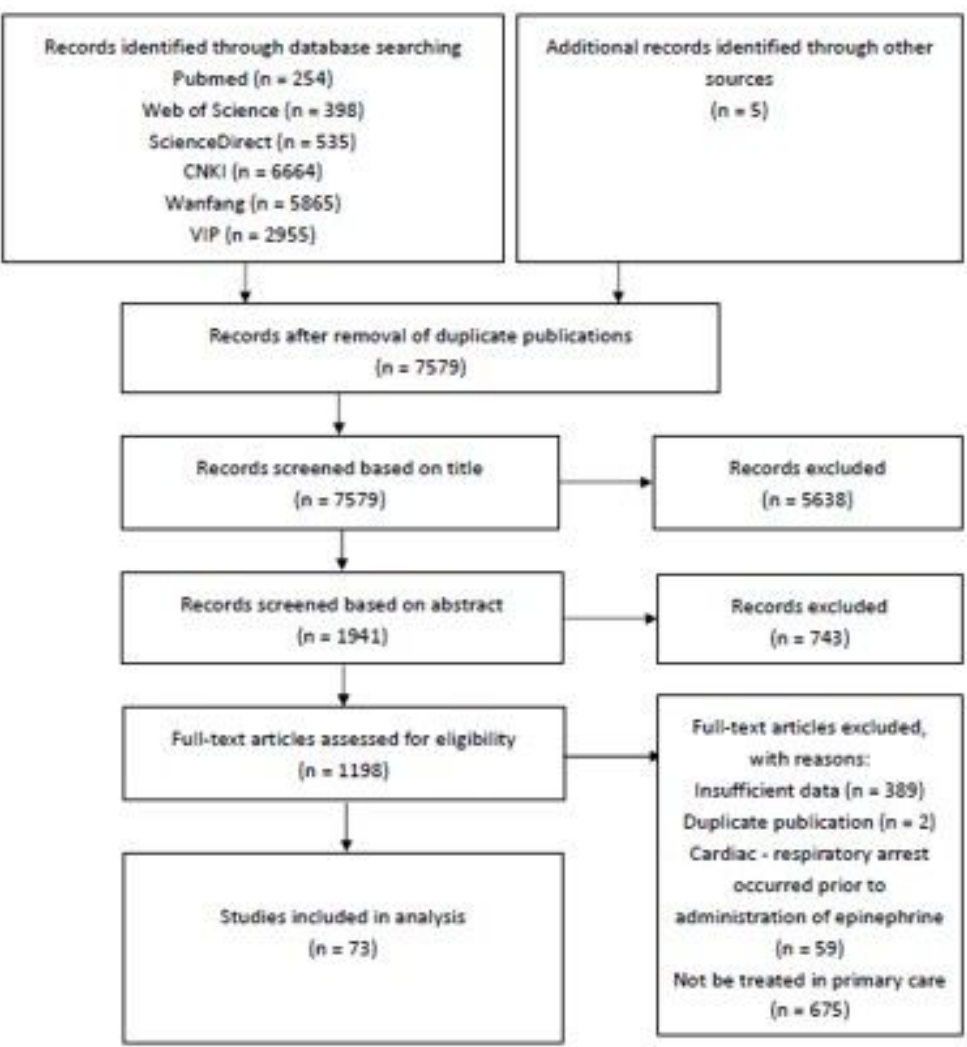

Figure 1

PRISMA flow diagram of the selection of studies. 